Original Article

\title{
Frequency of Infected Healthcare Workers and Factors Leading to Infection in Emergency Neurosurgical Trauma during COVID-19 Pandemic
}

\author{
Ehtisham Ahmad Khan Afridi ${ }^{1}$, Shoaib Zardad ${ }^{2}$, Shah Khalid ${ }^{1}$, Shahbaz Ali Khan ${ }^{1}$ \\ Aqsa Shehzadi ${ }^{1}$, Faiza ${ }^{3}$ \\ Departments of ${ }^{1}$ Neurosurgery, ${ }^{2}$ Orthopedic and ${ }^{3}$ Obstetrics \& Gynecology, Ayub Teaching Hospital, \\ Abbottabad - Pakistan
}

\section{ABSTRACT}

Objective: The aim of this study was to know the frequency of COVID-19 infection in healthcare workers and to identify the risk factors leading to infection in emergency neurosurgical trauma during COVID-19 pandemic.

Material and Methods: This descriptive cross-sectional study was conducted in the Department of Neurosurgery, Ayub Teaching Hospital. A total of 99 healthcare workers with an age range from $22-55$ years attending or carry emergency procedures with both male and female gender were included in the study. Age, gender, sign and symptoms, safety measures and COVID PCR reports were recorded.

Results: 12 (12.1\%) out of 99 healthcare workers got an infection with COVID-19. $83.3 \%$ of the infected healthcare workers were male while $16.6 \%$ were females. A maximum of the healthcare workers infected with COVID-19 was in the age range $31-40$ (50\%). Most of them were Doctors (66.6\%) followed by nursing staff (25\%). Low-grade fever and cough were the most common symptoms. The most important factors which affect the transmission of infection to healthcare workers were improper use of personal protective equipment (PPE), masks, gloves by healthcare professionals, and inability to maintain social distancing with the patients.

Conclusion: Among healthcare workers Doctors have the highest risk of getting an infection with COVID-19, followed by Nurses and Paramedics staff. Lack of social distancing and personnel protective equipment is associated with a high risk of infection with coronavirus disease. To protect healthcare workers from getting infections, proper personal protective equipment should be used. Early recognition of the infected patient and prompt isolation should be done to prevent or minimize the chain of transmission.

Keywords: COVID-19, Frequency, Risk factors, Healthcare workers.

Corresponding Author: Shah Khalid

Department of Neurosurgery, Ayub Teaching Hospital, Abbottabad - Pakistan

Email: shahkhalid23230@gmail.com
Date of Submission: 0-0-2021

Date of Revision: 0-0-2021

Date of Online Publishing: 30-6-2021

Date of Print: 30-6-2021

DOI: $10.36552 /$ pjns.v25i2.561 


\section{INTRODUCTION}

COVID-19 outbreak was first reported in Wuhan, Hubei province, china in late December 2019 and then rapidly became an increasing health concern globally. ${ }^{1}$ The extremely infectious disease is caused by coronavirus 2 (CoV-2), has a disastrous impact on the world population with more than 2.9 million deaths worldwide, emerging as the most substantial universal health crises after the influenza pandemic in 1918. ${ }^{2}$ World health organization in January 2020 declared the disease (COVID-19) as a public health crisis of international concern. ${ }^{3}$ The disease manifest in various symptoms spanning, from asymptomatic/ mild symptoms to critical illness and death. ${ }^{4}$ Route of transmission is via aerosolized droplets that are ejected through sneezing, coughing, and expiration. ${ }^{5}$ Health care workers are usually on the frontline during the COVID-19 pandemic and carry a high chance of getting an infection while taking care of patients. ${ }^{6}$ They are subjected to prolonged duty timings, mental stress, and tiredness. ${ }^{7}$ They represent a vulnerable target for infection due to their repeated exposure to highly contiguous patients and the inability of the healthcare facilities to deal with the unexpected increase in cases. ${ }^{8}$ They have a high risk of getting an infection during the COVID-19 Pandemic especially before transmission dynamics are entirely characterized. ${ }^{9}$ The incidence in healthcare workers was up to $10 \%$ of the confirmed cases reported in china and Italy, while in Spain $20.4 \%$ of the cases were among healthcare workers. ${ }^{3}$ Infection in healthcare workers can potentially exacerbate the chain of transmission in hospitals and outside healthcare facilities. ${ }^{10}$ Unprotected exposure, personnel contact, and potentials droplets are the factors that keep the healthcare workers at a high risk of infection. ${ }^{11}$ Nowadays, COVID-19 is the most serious threat to healthcare workers and causes the highest level of anxiety among them in many countries including Pakistan. Healthcare workers account for $3 \%$ of COVID-19 infections in
Pakistan, much lower from developed countries like Spain where COVID-19 infection in healthcare workers accounts for $20.4 \%$ of total reported cases. ${ }^{3}$ According to National Command and Operation Center (NCOC), more than 253 healthcare workers have been infected with the novel coronavirus across Pakistan till April 22, 2020. Most of them are doctors (49\%), while paramedics and other staff make up for 35\% and nurses $15 \%$. The aim of this study is to know the frequency of COVID-19 infection in healthcare workers and to identify the risk factors leading to infection in emergency neurosurgical trauma during the COVID-19 pandemic.

\section{MATERIAL AND METHODS}

\section{Study Design and study settings}

This descriptive cross-sectional study was conducted in the department of neurosurgery from 20 April 2020 to $10^{\text {th }}$ August 2020. Approval was taken from the hospital ethical committee. Informed consent was taken from all Healthcare workers $(n=99)$ included in this study. An inclusion and exclusion criteria were created.

\section{Inclusion Criteria}

Healthcare workers with ages range from $22-55$ years attending or carry emergency procedures with both male and female gender were included in the study.

\section{Exclusion Criteria}

Any healthcare worker with past history of COVID-19 was excluded from the study.

\section{Data Collection}

A total of 99 Healthcare workers were included in the study. Basic demographic information's, Designation, signs, and symptoms along with safety measures including personnel protective equipment (PPEs), face mask, gloves, etc., were 
recorded on pre-designed preformed. An initial chest X-ray was done to aid in diagnosis. The nasopharyngeal swab was taken and Infection with COVID-19 was confirmed by Real-time reverse transcriptase-polymerase chain reaction (RT-PCR) according to the standard protocol established by the world health organization (WHO). The data was analyzed using IBM SPSS 25.

\section{RESULTS}

\section{Gender Incidence}

Out of 99 healthcare workers included in this study, there were 27 (27.27\%) female and 72 (72.72\%) male patients.

\section{Age Distribution}

The age ranged between 22 to 55 years. Most of the healthcare workers included in this study were in the age range $30-40(41.4 \%)$ years (Table 1$)$.

Table 1: Age Distribution.

$\begin{array}{cc}\text { Age Range } & \mathbf{n}(\%) \\ 22-30 & 22(22.2 \%) \\ 31-40 & 41(41.4 \%) \\ 41-50 & 23(23.2 \%) \\ 51-55 & 13(13.3 \%)\end{array}$

\section{Incidence of Infection in Healthcare Workers}

The majority of them were nursing staff $(31.3 \%)$ followed by doctors (24.2\%) and paramedics (25.2\%). 12 (12.1\%) out of 99 healthcare workers got an infection with COVID-19. 83.3\% of the infected healthcare workers were male while $16.6 \%$ were females. Maximum of the healthcare workers infected with COVID-19 were in the age range 31 - 40 (50\%) years (Figure 1). Most of them were Doctors (66.6\%) followed by Nursing staff (25\%).

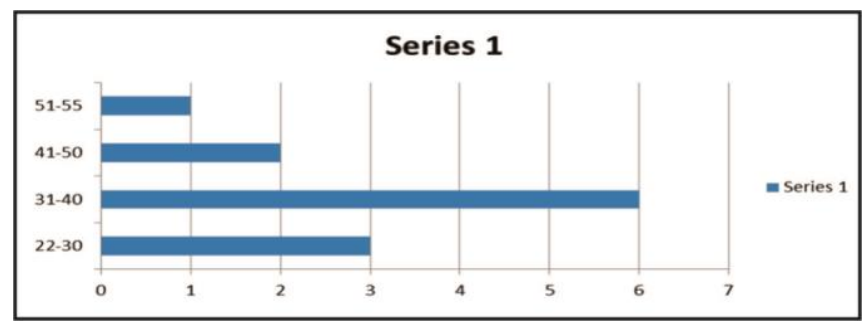

Figure 1: Age distribution of infected healthcare workers.

\section{Clinical Manifestations}

Cough and low grade-fever were the most common symptoms. 7 (58.3\%) of the infected healthcare also reported shortness of breath and chest discomfort. 2 (16.6\%) out of 12 infected healthcare workers reported gastroenteritis along with fever and dry cough. The mean duration between signs and symptoms to diagnosis with PCR was 5.7 days.

\section{Risk Factors}

The most important factors which affected the transmission of infection to healthcare workers was improper use of personal protective equipment (PPE), masks, gloves by healthcare professionals and inability to maintain social distancing with the patients. Asymptomatic patients and especially undiagnosed symptomatic patients greatly affected the healthcare workers.

\section{DISCUSSION}

Health care workers are usually on the frontline during a pandemic and carry a high chance of getting infections while treating patients. Healthcare professionals are usually at a high risk of acquiring infections during COVID -19 outbreaks. $^{12}$ Up-to-date little is known about COVID -19 transmission in healthcare settings. Studies from Hong Kong, Singapore, and Illinois have reported no infection in healthcare professionals exposed to infected patients with coronavirus disease. ${ }^{13,14}$ it might be because of that, most of the healthcare workers were wearing 
precautions against contact, droplets, or airborne transmission. As a result of the spread of COVID19 , it is usually difficult to know whether a healthcare professional is infected in a hospital or in some community. This study helps which healthcare worker acquired the infection and which did not acquire infection and guides us to protect our healthcare workers on the frontline.

The frequency of infected healthcare workers in our study was $12.1 \%$ with male $8.3 \%$ and female $1.6 \%$ respectively. This high percentage of infection largely depends on the lack of precautions taken by healthcare professionals. Initially, in the hospitals, even the simple surgical mask was not available; peoples use to buy it from outside.

Still, our frequency is lower than the results which are showed by North-Eastern Italy that is $16.2 \%$ of all infected healthcare workers that could be attributed to the decrease in virulence capacity of the virus over time. But our results are much higher than the results showed in China and United States, that is $3.8 \%$ and $4.4 \%$, respectively. ${ }^{15}$ this could be due to highly precautions and equipment available for their healthcare workers.

We identified many factors that probably lead to an increased infection rate in healthcare workers. First, there was a lack of knowledge of this new disease and a low level of safety measures combating the COVID-19 outbreaks, especially in the first few weeks of outbreaks in Pakistan. In emergency neurosurgical trauma initially, there was no simple surgical mask for healthcare workers. Peoples used to buy it from outside. Second, healthcare workers cannot maintain social distancing in resuscitation and operating upon neurosurgical patients. In addition, there could be some patients who may have atypical symptoms in the incubation period of COVID-19. Throughout these circumstances, the virus was transmitted to healthcare workers without full protective gear.

\section{CONCLUSION}

Among healthcare workers, Doctors have the highest risk of getting an infection with COVID19, followed by Nurses and Paramedics staff. Lack of social distancing and personnel protective equipment is associated with a high risk of infection with coronavirus disease. To protect healthcare workers from getting infections, proper personal protective equipment should be used. Early recognition of the infected patient and prompt isolation should be done to prevent or minimize the chain of transmission.

\section{REFERENCES}

1. Piapan $L$, De Michieli $P$, Ronchese $F$, Rui $F$, Mauro $M$, Peresson $M$, Segat $L$, D'Agaro P, Negro C, Bovenzi M, Filon FL. COVID-19 outbreak in healthcare workers in Trieste hospitals (NorthEastern Italy). The Journal of Hospital Infection, 2020 Aug. 14.

2. Cascella M, Rajnik M, Aleem A, Dulebohn S, Di Napoli R. Features, evaluation, and treatment of coronavirus (COVID-19). Stat Pearls, 2021 Apr. 20.

3. Selles NA, Valentí PG, Sanchez PC, Muriel JGM, Molina VMS, Maldonado $\mathrm{MH}$ et al. Frequency, Associated Risk Factors, and Characteristics of COVID-19 among Healthcare Personnel in a Spanish Health Department. American Journal of Preventive Medicine Am J Prev Med. 2020; 59 (6): e221-e229.

4. Esakandari $\mathrm{H}$, Afjadi MN, Afjadi JF, Farahmandian $\mathrm{N}$, Miresmaeili SM, Bahraini E. A comprehensive review of COVID-19 characteristics. Biol Proceed Online, 2020; 22: 19.

5. Wang $D, H u B, H u$ C, et al. Clinical characteristics of 138 hospitalized patients with 2019 novel coronavirus-infected pneumonia in Wuhan, China. JAMA. 2020: 1585.

6. Schwartz J, king CC, Yen MY. Protecting health care workers during the covid-19 corona virus outbreak-Lesson from Taiwan's SARS response. Clin Infect Dis. 2020 Mar. 12; (Ciaa 225).

7. World Health Organization (WHO). Corona virus disease 2019 (covid-19): Situation report-82. Subject in Focus: Infections in healthcare workers. April 11, 2020. 
8. Al Abri ZG, Al Zeedi MA, Al Lawati AA. Risk Factors Associated with COVID-19 Infected Healthcare Workers in Muscat Governorate, Oman. Journal of Primary Care \& Community Health. 2021. Feb;12:2150132721995454.

9. Ghinai I, Mcpherson TD, Hunter JC, et al. Illinois covid-19 Investigation Team. First known person to person transmission of severe acute respiratory syndrome corona virus 2 (SARS-COV2) in the USA. Lancet, 2020; 395: 1137-44.

10. Gholami M, Fawad I, Shadan S, Rowaiee R, Ghanem H, Khamis AH, et al. COVID-19 and healthcare workers: A systematic review and metaanalysis. International Journal of Infectious Diseases IJID. 2021; 104: 335-346.

11. Hussein $\mathrm{H}$, Alemu ZA. Risk of COVID-19 Infection and Associated Factors among Healthcare Workers: A Cross-Sectional Study at Eke Kotzebue Treatment Center in Ethiopia. International Journal of General Medicine, 2021; 14: 1763-1772.

12. Heinzerling A, Stuckey PM, Scheuer $T, X u K$, Perkins KM, Resseger H, Magill S, Verani JR, Jain S,
Acosta M, Epson E. Transmission of COVID-19 to health care personnel during exposures to a hospitalized patient-Solano County, California, February, 2020.

13. Ng K, Poon BH, Kiat Puar TH, Shan Quah JL, Loh WJ, Wong YJ, Tan TY, Raghuram J. COVID-19 and the risk to health care workers: a case report. Annals of Internal Medicine, 2020; 2; 172 (11): 766 7.

14. Cheng VC, Wong SC, Chen JH, Yip CC, Chuang VW, Tsang OT, Sridhar S, Chan JF, Ho PL, Yuen KY. Escalating infection control response to the rapidly evolving epidemiology of the coronavirus disease 2019 (COVID-19) due to SARS-CoV-2 in Hong Kong. Infection Control \& Hospital Epidemiology, 2020; 41 (5): 493-8.

15. Wu Z, McGoogan JM. Characteristics of and important lessons from the coronavirus disease 2019 (COVID-19) outbreak in China: summary of a report of 72314 cases from the Chinese Center for Disease Control and Prevention. JAMA. 2020;] 7; 323 (13): 1239-42.

\section{Additional Information}

Disclosures: Authors report no conflict of interest.

Ethical Review Board Approval: The study was conformed to the ethical review board requirements.

Human Subjects: Consent was obtained by all patients/participants in this study.

Conflicts of Interest:

In compliance with the ICMJE uniform disclosure form, all authors declare the following:

Financial Relationships: All authors have declared that they have no financial relationships at present or within the previous three years with any organizations that might have an interest in the submitted work.

Other Relationships: All authors have declared that there are no other relationships or activities that could appear to have influenced the submitted work.

\section{AUTHORS CONTRIBUTIONS}

\begin{tabular}{|l|l|l|}
\hline Sr.\# & Author's Full Name & Intellectual Contribution to Paper in Terms of: \\
\hline 1. & Ehtisham Ahmad Khan Afridi & Study design and methodology. \\
\hline 2. & Shoaib Zardad & Paper writing, referencing, and data calculations. \\
\hline 3. & Shah Khalid & Data collection and calculations. \\
\hline 4. & Shahbaz Ali Khan & Analysis of data and interpretation of results etc. \\
\hline 5. & Aqsa Shehzadi & Literature review and manuscript writing. \\
\hline 6. & Faiza & Analysis of data and quality insurer. \\
\hline
\end{tabular}

